novedosas, sino a seguir las más comunes $\mathrm{y}$ aprobadas ${ }^{76}$ ? Es posible. Además, el tema del intelecto agente fue un caballo de batalla permanente durante toda su carrera académica. ${ }^{77} \mathrm{Tal}$ vez por no echar más leña al fuego no dijo más. En cualquier caso, se trata un tema que por su relevancia y profundidad merece la pena seguir investigando. ${ }^{78}$

Una última cuestión ¿por qué el intelecto agente se sirve de instrumentos innatos para conocer lo humano inferior (sindéresis), para conocer lo real principial extramental (intellectus), e incluso para conocerse a la propia persona (sabiduría). Se puede proponer esta solución: para no confundir su tema propio con el de aquéllos. ¿Cuál es su tema propio? Una realidad que sea más que humana (más que inteligencia y voluntad), más que realidad principial fundante (más que acto de ser impersonal) y más que persona humana. Pero eso, sólo Dios.

76 Acta Capisulerum Generalium Ordinis Praedicatorum, B.M., REICHERT (ed.), "Monumentos Ordinis Fratrum Praedicatorum Historica", t. 3 (Typ. Polyg. S.C. Propaganda Fidei, Romae, 1898, vol. 1, p. 29, lin. 5-6).

${ }^{77}$ Cf. mis trabajos: "El entendimiento agente según Tomás de Aquino", Revista Española de Filosofia Medieval 9 (2002), pp. 105-124; "La critica tomista a la interpretación griega y neoplatónica del intelecto agente", Actas del XI Congreso Internacional de Filosofia Medieval, Oporto (agosto 2002), pp. 26-32, en prensa; "La crítica tomista a la interpretación árabe y judía del intelecto agente", Espiritu, LII (2003) 128, pp207-226; "Los filósofos del s. XIII que negaron el intelecto agente. Revisión crítica", en Dar razón de la esperanza, Pamplona, EUNSA, 2994 pp. 1277-1300; "Las tesis de los filósofos del s. XIII que afirmaron el intelecto agente", en Fuentes de la metafisica altomedieval, Pamplona, EUNSA, 2004, en prensa.

78 He tratado de este tema en mi trabajo El conocer personal. Estudio del entendimiento agente según Leonardo Polo, Cuadernos de Anuario Filosófico, $n^{\circ}$ 163, Pamplona: Servicio de Publicaciones de la Universidad de Navarra, 2003.

\section{El amor de sí mismo según el pensamiento de Tomás De Aquino}

Ezequiel Téllez Maqueo

Universidad Autónoma de Aguascalientes

\begin{abstract}
Aunque tradicionalmente es asociada con una virtud por la que los hombres son capaces de querer y procurar el bien ajeno, según Tomás la caridad no implica el olvido absoluto de uno mismo, sino que comprende el amor de si mismo que, a diferencia de lo que proponen ciertas lecturas del budismo, el totalitarismo, etcétera, es no sólo algo necesario y deleitable, sino que además descansa en una exigencia de plenitud existencial, i.e., en el deseo natural de alcanzar la felicidad, y es la raiz de todo tipo de amor, principalmente es el modelo y medida del amor a las demás personas. Este artículo se enfoca al estudio de sus características filosóficas, antropológicas y éticas.
\end{abstract}

\section{Introducción}

El escritor francés André Malraux, quien murió en 1976, solía decir que el siglo XXI sería el siglo de la religión o no sería. Esto, además de cierto, es algo cada vez más constatable. La primera vez que escuché un comentario acerca del budismo, fue durante mis estudios de derecho allá por 1987 en la Universidad Nacional Autónoma de México, y provino de un inquieto y connotado profesor de derecho civil, que tuvo la osadía intelectual de comparar la moral cristiana con la moral budista. En aquella década a finales de los ochentas (caracterizada por una hipertrofia del laicismo en los práctica ordenes de la vida cultural de diversos paises, que en la práctica se traducía en un silencio cuasi absoluto por lo que al tema liberación, que aún camperen concepción de la llamada teología de la qué hablar que aún campeaba fuertemente y que aún sigue dando de qué hablar en ciertos ambientes indigenistas), era menos común de lo 
que actualmente sucede una manifestación de las propias preferencias religiosas o el confrontar las bases éticas y metafísicas sobre las que descansan los diversos credos existentes. Hoy, en cambio, parece de lo más corriente querer iniciar de modo personal la búsqueda de la verdad impulsada por un resurgimiento como el que actualmente se produce de los intereses espirituales, autoperfectivos y esotéricos. La gente tiene necesidad de vida espiritual, y más aún, de una espiritualidad vivida, lo que hace veinte años era, si no menos real, probablemente menos ostensible.

Por otro lado, la práctica ausencia del discurso religioso en el ambiente académico hace dos décadas podía resultar bastante lógica si se toma en cuenta que el socialismo aún seguia ejerciendo un influjo filosófico acentuado como sistema de pensamiento alternativo al capitalismo salvaje: de modo que el socialismo parecía más apropiado que cualquier otra doctrina social para hacer contrapeso a los excesos del capitalismo imperante de aquella época. Pero con la caída formal de los regímenes políticos socialistas en Europa oriental, el cristianismo, y en general, la religión, parecen estar volviendo a recuperar la importancia de la que carecieron durante los últimos treinta años del siglo $\mathrm{XX}$, de modo que el movimiento ecuménico, junto con la proliferación de ciertos movimientos neorreligiosos, están volviendo necesaria a diversos especialistas una revisión del hecho religioso como fenómeno cultural, lo que propiciará en los próximos años un estudio más serio del papel de Dios en la vida de los individuos de un determinado país, sea laico o no lo sea.

En opinión de aquel memorable profesor, el budismo consistía en una religión más exigente que el cristianismo: pues mientras el cristianismo pregona la necesidad de amar al prójimo en la medida del propio amor a sí mismo, el budismo iría más lejos, al proponer la necesidad de amar al prójimo más que a nosotros mismos. La única reacción de mi pensamiento a dicha aseveración consistía en suponer que de nada sirve poder amar al prójimo más que a uno mismo, si no se es capaz de amar a los propios enemigos. ¿Quién puede decir que es más dificil lo primero que lo segundo? Si se tratara de tener que inclinarse por la religión más ardua, o si la verdad de un determinado credo dependiera de su mayor rigor ascético o moral, pienso que el cristianismo no se quedaría atrás respecto del budismo.

Con el paso del tiempo he seguido meditando sobre el particular en orden a una tentativa de respuesta, y he llegado a la conclusión de que tan inconveniente es querer plantearse metas tan elevadas a un sujeto, y por tanto, tan inasequibles al mismo, como el no plantearse objetivos de crecimiento personal y espiritual, aunque inicialmente sean sólo modestos. Centrados en esta segunda postura ética, Agustín de Hipona ha demostrado la necesidad de alejarnos de toda inquietud pelagiana, es decir, de evitar instalarnos en el lábil terreno del naturalismo (bien sea de corte burgués o rousseauniano) según el cual no existe el mal moral ni la necesidad de luchar consigo mismo dado que el desorden interno que el propio sujeto experimenta, principalmente en cuanto al dominio de la concupiscencia se refiere, no pasaría de ser un simple mito teológico creado por los encomiastas del pecado original. Pero Agustín reconoce, haciéndose eco de Pablo, que en el hombre existe una serie de tendencias descarriadas, es decir, un desorden natural por el que a pesar de saber lo que es bueno moralmente, en ocasiones el individuo actúa en contra de lo que considera precisamente como tal. Lo importante para Agustín es admitir que en el hombre están puestos los elementos para evitar que viva en esta contradicción; y que con ayuda de la gracia divina ello es aún más factible. Esto es lo que hace posible y necesaria una $\alpha) v \alpha \gamma \omega \gamma \eta /$, es decir, un plantearse metas de ascenso espiritual, de modo que las tendencias más nobles del ser humano como el deber y la virtud, tienen su razón de ser y pueden alcanzar su debida y natural satisfacción. Como se suele decir en términos coloquiales: "lo que está al alcance del hombre debe exceder su puño. Si no, para qué es el cielo".

Pero hablando del otro extremo, es decir, de la necesidad de no imponerse metas tan elevadas que en cierto momento puedan ser inalcanzables o definitivamente inaccesibles, to relevante no es que en caso de no alcanzarse, ello pueda provocar un índice elevado de frustración humana en el terreno psicológico (lo cual, por otro lado, es verdadero). Si la frustración está de acuerdo con la necesidad de ser conscientes de que no se puede hacer todo, quizás la frustración 
no sea tan mala como la pintan ciertos psicólogos. Más importante es lo que de ello se desprende en el terreno ético, en el cual resulta evidente el papel que las motivaciones humanas personales desempeñan para que el hombre actúe correctamente. Para que el hombre alcance el bien evidentemente debe tender a él, lo que sólo se consigue cuando el sujeto de una acción moral específica se considera capaz de alcanzarla. Si el hombre tiende a lo bueno es porque está consciente de que ello se encuentra al alcance de sus posibilidades (otro asunto consiste en determinar dónde se halla el bien o qué es lo bueno, lo que de momento no es mi intención aclarar).

\section{Nirvana budista versus anagogé cristiana}

Estas consideraciones iniciales conducen irremediablemente a plantear si la necesidad de amar al prójimo más que a uno mismo, tal como aparentemente está prevista por el budismo ¿no consistirá precisamente en una meta moral tan exigente que rebasa las propias capacidades del hombre, quien en la vida ordinaria y en el mejor de los casos, apenas es capaz de amar siquiera a los otros en la medida de sí mismo? En un mundo en que la difusión de los estados depresivos es preocupante, $y$ en el que el nivel de autoestima de las personas es sumamente bajo, la verdadera importancia de amarse a sí mismo es algo que habrá de replantearse, por tratarse de una condición de posibilidad para el amor hacia los demás; por ser el límite del amor hacia los demás, y sobre todo, por tratarse de una obligación moral de cada individuo, que es la tesis que aqui se intenta justificar.

El amor ordenado de sí mismo, cuando es correctamente entendido, lejos de ser un acto de soberbia o pusilanimidad, constituye una virtud a la que Tomás de Aquino denomina con el nombre de magnanimidad, y que se define como "el compromiso que el espíritu se impone voluntariamente de tender hacia lo sublime". El magnánimo aspira a lo extraordinario y se hace digno de ello, pues lo hace bajo la conciencia de que cuenta con las

\footnotetext{
'Summa Theologiae, II-II, q. 129, a. I.
}

capacidades para alcanzarlo, que es lo que lo distingue del presuntuoso, quien toma por sublime lo que no es tal (por ejemplo, la alcurnia, las riquezas o el boato, el propio cuerpo) o espera algo que excede sus capacidades.

Esto no debe llevar a pensar en el magnánimo como un ser engreído. Quienes conozcan de pasada el tratado sobre la humildad del doctor napolitano, saben que no existe ninguna frase que pueda dar lugar a pensar que el humilde se identifica con aquel que mantiene una constante actitud de autorreproche, depreciación del propio ser o minusvaloración de los propios méritos. No hay que extrañarse, en cambio, de que la autoconsideración moral que un sujeto pueda tener de sí mismo y de sus propias capacidades, en el contexto del pensamiento budista esté caracterizada por la anulación de los propios deseos, es decir, por una deminutio de la propia personalidad, en franca concordancia con la conocida doctrina éticoestoica de la ò $\alpha \propto \rho \alpha \xi ̧ \zeta \iota_{\alpha}$ o imperturbabilidad del ánimo. A pesar de que algunos estoicos como Séneca, hablan de la existencia de ciertos afectos nobles । ( $\varepsilon v ้ \pi \alpha \dot{\theta} \theta \varepsilon \alpha \alpha),{ }^{2}$ e incluso éste último llega a hablar de tener confianza en sí mismo, ${ }^{3}$ la tónica general del discurso estoico es que "las pasiones son torcimientos de la razón"4 y todas se apoyan en un error. Por tanto, la eliminación y la ausencia de cualquier pasión está más próxima a la auténtica felicidad, y las pasiones representan más bien una perturbación $(\tau \alpha \rho \alpha \chi \eta ்)$ del alma.

Algunos autores, han entrado en el terreno de la valoración ética de esta doctrina. Así, por ejemplo, dice Narciso Irala: "es necesario ponderar suficientemente si es o no felicidad el Nirvana budista, que pretendiendo la deificación del ser humano, va mutilando la vida psíquica anulando así toda actividad y deseo (anulación negativa que implica empobrecimiento)".5 También Juan Pablo II, hablando de la soteriología negativa del budismo, señala que para éste la salvación

\footnotetext{
2 Epistolae ad Lucilium, 104, 3.

${ }^{3}$ Epistolae ad Lucilium, 94,46

${ }^{4}$ Cicerón: Disputationes Tusculanae, IV, $\$ 80$. Cf. De finibus, III, § 35; y Tusc. IV, $\S 25$.

${ }^{5}$ Control cerebrai y emocional, México: Librería Clavería 1978, p. 24.
} 
nos viene del desapego del mundo. Pero añade que "la plenitud de tal desapego no es la unión con Dios, sino el llamado Nirvana, o sea, un estado de perfecta indiferencia respecto del mundo", 6 algo que, por otro lado, se entiende como abiertamente inconsectario con el cristianismo, y específicamente, con el pensamiento de san Juan de la Cruz, para quien, la necesidad de purificación y de desprendimiento del mundo de los sentidos "no se concibe como un fin en sí mismo", ' sino que es propuesta por el doctor de la Iglesia "para unirse a lo que está fuera del mundo, y no se trata del Nirvana, sino de un Dios personal". ${ }^{8}$ De manera que "la unión con Él no se realiza sólo en la vía de la purificación, sino también en la del amor". 9

Nada más ajeno a mi propósito que realizar aquí una crítica al patrimonio espiritual del budismo. En cambio, considero conveniente mencionar como de interés sociológico, que para algunos especialistas, en la base de ciertos fenómenos sociales como el retraso tecnológico y el subdesarrollo, tan arraigados en la mente de los habitantes de ciertos países asiáticos, subyacen como factor psicológico los presupuestos de la doctrina ética budista, en los términos en que aquí lo he descrito. Tal es el parecer de Piero Gheddo, quien afirma categóricamente:

El desarrollo de un pueblo tiene que nacer de dentro, de una revolución cultural que movilice aquellas culturas estáticas que no disponen de estimulos interiores para crear un mundo mejor. El budismo, por ejemplo, no justifica la democracia ni la justicia social ni ninguna otra idea nueva. Todo está bien como está, no hay que cambiar nada porque, según la ley del 'karma', cada uno tiene lo que le conviene para su

\footnotetext{
${ }^{6}$ Cruzando el umbral de la esperanza, Barcelona: Plaza \& Janes 1994, p. 100

7 Cruzando el umbral de la esperanza..., p. 101.

${ }^{8}$ Cruzando el umbral de la esperanza..., p. 101

${ }^{9}$ Cruzando el umbral de la esperanza..., p. 101.
}

vida. El que es paria, debe tener paciencia, pues ya renacerá brahmán en la vida siguiente. ${ }^{10}$

Si lo anterior es verdad, entonces el amor de sí mismo adquiere una relevancia extraordinaria. Porque el amor de la propia persona es justamente uno de esos estímulos de los que dispone el hombre para cambiar y crear una sociedad más justa y democrática. Cuando los pueblos cuentan entre sus habitantes con un número suficiente de personas poseedoras de un elevado nivel de autoestima, signo de lo cual es el hecho de que la gente percibe un gusto por el propio trabajo desarrollado y experimenta una satisfacción por practicar la virtud porque sabe que ello redunda en su propio beneficio y porque es consciente de que ello la conduce a cotas elevadas de crecimiento personal, entonces se está en mejores condiciones de abandonar el estado de subdesarrollo generalizado de todo un pueblo o nación.

Por tanto, hablar de la ética budista versus moral tomista-cristiana permite descubrir lo importante que resulta para la segunda el trabajo, no sólo comunitario sino también individual. Después de todo, la posibilidad de generar un desarrollo social dependerá en gran medida de la determinación de qué tan estimable sea la ascética personal, es decir, dependerá de la importancia que revista el vencimiento propio y la lucha interior para cada sujeto de los que integran una sociedad. A este respecto, dice Gheddo, "he escuchado infinidad de veces en países musulmanes, asiáticos y africanos en general, que el concepto de empeño en el trabajo es lo que el cristianismo ha exportado; para la tradición local, en cambio, la aspiración es poder vivir sin trabajar"."1

10 Diego CONTRERAS: "La mejor ayuda al desarrollo es la cultura", Acepiensa XXXIV-16.5 (2003), p. 1.

11 D. Contreras: "La mejor ayuda...", p. 2. También Fulton J. SheEn tiene una opinión parecida: "Según el pensamiento oriental, todos estamos más o menos determinados por un sino o hado absoluto, por un karma, por el proceso cíclico de la naturaleza, e incluso según una religión las personas están tan determinadas por la voluntad de Dios que es prácticamente imposible todo progreso humano. El progreso en Oriente consiste en la resignación pasiva, porque el individuo no es más que un destello surgido del gran sol por la mañana, para volver a él por la noche, en el inmenso girar del universo" (La vida hace pensar, Juan Flors, Barcelona, 1956, p. 269). 


\section{Necesidad de amarse a sí mismo}

Hablar del budismo en un trabajo acerca del amor de sí mismo tiene sentido porque el budismo no concede la suficiente importancia al amor por la propia persona. El budismo es en cierta medida incompatible con el amor de sí mismo, y con ello se instala en un terreno divergente al tomismo. En efecto, sin caer en la exaltación del egocentrismo y la mezquindad como motores del comportamiento humano, $y$ sin negar la posibilidad que el hombre tiene de hacer el bien para los demás, ${ }^{12}$ como por ejemplo, a los amigos, los familiares o la patria misma, y al extremo de morir si ello fuese necesario, como no sólo el derecho romano lo contemplaba sino además el cristianismo ("no hay mayor amigo que el que da la vida por otro"), Tomás de Aquino considera que el hombre puede y debe amarse a sí mismo.

Pero al afirmarlo, no está pensando, como tampoco Aristóteles lo hace, en cualquier clase de hombre, sino únicamente en el hombre bueno, es decir, el virtuoso, ya que, "al practicar acciones esmeradas, se hace un bien a si mismo". ${ }^{13}$ En cambio, "el hombre malo no debe amarse a sí mismo, precisamente porque al seguir sus malas pasiones, se daña a sí mismo y a sus prójimos". 14

12 No en valde dice Aristóteles que: "Amar es querer un bien para el otro": Rhetorica, 1I, c. 4, 1380b, 35-36.

13 ARISTÓteles: Ethica Nicomachea, 1169a, 12-13. Y en otra de sus obras dice el Estagirita que: "Cada uno se tiene amor a sí mismo, y ello es un sentimiento natural. Se censura con razón el egoísmo, pero esto no consiste en amarse a sí mismo, sino en amarse más de lo que se debe, como el caso del amor al dinero, ya que todos, por asI decirlo, aman cada una de estas cosas" (Politica, 1263b 2-5). Cf. ARISTÓTELES, Politica, 1342a 25: "A cada uno le produce placer lo familiar a su naturaleza", asi como: Rethorica, 1371b 20: "siendo todos amantes de si mismos, forzosamente les serán placenteras a todos sus propias cosas, así sus obras como sus palabras".

14 ARISTóteles: Ethica Nicomachea, 1169a, 14-15. Aquí se está refiriendo Aristóteles al amor de sl mismo, que en vez de ser algo bueno es criticable. Se trata de la clase de personas que en el amarse a si mismas no lo hacen porque obedezcan a la razón, sino que al hacerlo obedecen a su naturaleza sensible. Y ello, como bien explica santo Tomás en otro lugar, "no es amarse verdaderamente a sí mismo, es decir, según la naturaleza racional, que dicta que amemos para nosotros los bienes que atanen a la perfección de la razón" (Summa Theologiae: II-II, q. 25, a. 4, ad 3um).
En otras palabras, el hombre puede ser feliz, y a fin de alcanzar su felicidad, debe aplicarse a la virtud. Si al hombre no le fuera lícito amarse a sí mismo, ello significaría que no le es lícito desear un bien para si, y por tanto, ni siquiera la virtud. Y si no deseara la virtud jamás se perfeccionaría ni llegaria a ser bueno, con lo que la moral carecería de sentido. Pero afortunadamente al hombre le es lícito desear la virtud para sí mismo. Más aún le es natural, necesario y conveniente desearla para sí: "si el hombre es virtuoso debe querer lo bueno para sí, porque cada uno quiere bienes para sí mismo".15

Este amor de sí es tan legítimo, tan propio del hombre por el simple hecho de existir, que, como explica santo Tomás inspirándose en Aristóteles:

Si aconteciera que un hombre pudiera transformarse en otra cosa, como ocurre con las fábulas, en las que un hombre se convierte en piedra o asno, nadie se preocuparía si eso en lo cual se transformase tuviese todos los bienes, [y por tanto, tampoco le interesaria transformarse] porque cada cual quiere ser si mismo en cuanto conserva eso que él mismo es. ${ }^{16}$

En otras palabras, si fuera posible a un sujeto, que, para adquirir todos los bienes, se sometiera a un cambio de apariencia, nadie elegiría tal opción si para ello tuviera que renunciar también a ser él mismo. Lo que aquí está en juego es la propia mismidad, algo que la antropología filosófica suelen denominar, intimidad substancial. Se podrá renunciar a ser humano, pero no a ser uno mismo. Al transformarse en lluvia de oro, para poder llegar hasta Dánae, Zeus mudó de apariencia, pero no dejó de ser Zeus. Y si para tener todos los bienes, es decir, para ser Dios, una persona tuviera que renunciar a ser lo que es, según Tomás, cualquier persona preferiría seguir siendo lo que es: es decir, ella misma. Pues sería bueno tener todos los bienes posibles, pero a condición de no perder el propio Yo. ¿Y qué es precisamente lo que nos singulariza? ¿Qué es aquello que no

15 In decem libros Ethicorum ad Nicomachum expositio, lib. IX, lect. IV, n. 1806

${ }^{16}$ In decem libros Ethicorum ad Nicomachum expositio, lib. IX, lect. IV, n. 1807 
podemos dejar de ser, ya que renunciar a ello equivaldría a renunciar a ser lo que se es? Sin mayor dilación, responde santo Tomás: el pensamiento. Para Tomás, el hombre puede en cierto modo ser su cuerpo, su carácter. Incluso pienso que el Angélico aceptaría (aunque con sus correspondientes reparos) que el hombre es lo que come. Pero sobre todo, el hombre es lo que piensa. El propio entendimiento es la vida misma de uno, el ser propio de cada uno. Pues basándose en Aristóteles, "el intelecto constituye al parecer lo que es cada hombre", 17 y "el ser de cada hombre parece consistir en su pensamiento". 18

Esto es así porque el hombre podrá cambiar de manera de pensar, pero no puede renunciar a tener un pensamiento, es decir, unos conocimientos tomados a partir de una vida, una experiencia pasada, que es lo que le individualiza y lo que conforma la propia vida. No hay dos entendimientos completamente iguales, porque no hay dos vidas completamente idénticas. El entendimiento de cada uno es lo que está menos sujeto a cambio dentro de un ser humano, y por eso, la personalidad de cada hombre está configurada por su propio pensamiento. Soy lo que pienso, soy lo que sé. $Y$ esto es lo más propio de mí. Y nadie querría renunciar a esto aunque a cambio se le ofreciera tener todos los bienes posibles.

El amor que uno siente por sí mismo, es algo a lo que se tiende naturalmente aun antes de que se alcance la virtud. Es un hecho que el hombre desea para sí el bien, prescindiendo de la forma de entenderlo. Lo desea y procura aun antes de ser virtuoso. No es que primero tenga que cambiar o ser alguien distinto de lo que soy, y luego, cuando lo haya "merecido", desearé este bien para mí. No es eso: lo quiero ahora y para mí tal cual soy en este mismo momento, esté yo o no de acuerdo conmigo mismo, haya concordia conmigo mismo o no la haya. Porque incluso cuando nos hacemos reproches, lo hacemos desde aquellas tendencias y valores que consideramos que pertenecen a nuestra esencia, desde lo que consideramos como lo mejor para nosotros.

\footnotetext{
${ }^{17}$ Ethica Nicomachea, 1166a, 22

${ }^{18}$ Ethica Nicomachea, 1166a, 23.
}

\section{El amor propio como exigencia de plenitud existencial}

Según santo Tomás, esto es así, y no hay que lamentarse de ello, ya que en definitiva, así estamos hechos, y por razón de nuestro ser de criaturas, en el mismo momento de recibir la creación fuimos lanzados por el camino de la propia plenitud, de la tendencia a la felicidad y a la realización de todo aquello que está contenido en germen dentro de nosotros. Dios ha creado todas las cosas para que sean. $\mathrm{Y}$ todas las cosas tienden a ser lo que son. El apetito de ser es un apetito natural de las creaturas. Y por eso, el amor de sí mismo es completamente legitimo, porque cuando el hombre se ama a sí, es porque en el fondo quiere mantenerse en su ser. Esto es lo que hace que el amor de sí mismo constituya una exigencia de plenitud existencial. La misma exigencia por la que el hombre está llamado a "querer su felicidad por naturaleza y necesariamente". ${ }^{19}$ La felicidad es "el conjunto de todas aquellas cosas que la voluntad es incapaz de no querer", ${ }^{20}$ de las que el amor de sí mismo es precisamente una de ellas.

Es sabido que para la adquisición de la virtud, el hombre debe transitar por distritos incómodos. Pero una vez adquirida la virtud, el virtuoso se encuentra con que su práctica no sólo le es útil, y necesaria, sino además gozosa. La práctica de la virtud proporciona un placer sensible e intelectual. Esto es lo que suscita el deseo por ella. Detectar con mi inteligencia que la virtud es buena para mi me lleva a amarla, a quererla para mí, y por tanto, a amarme en cierto modo.

Este hecho de que la virtud tenga como efecto un placer, hace pensar en otro aspecto: que para Tomás es indeseable la práctica de la virtud por la virtud misma, ${ }^{21}$ tal como había sido planteado por los estoicos siglos atrás, o como será planteado en el siglo XVIII por Kant, para quien la virtud tiene en sí misma su recompensa. No es mi

${ }^{19}$ Summa Theologiae, 1, q. 94, a. 1.

${ }^{20}$ Summa Theologiae, I-II, q. 10, a. 2.

21 Amamos la virtud no por ser algo bueno en sí mismo, sino en la medida en qúe por ella nos hacemos buenos: cf. TOMÁS DE AQUINO, In librum Beati Dionysii "De divinis nominibus", lect. X, cap. IV, n. 428. 
intención aquí explicar si la actitud moral ética o kantiana es inhumana o se encamina irremediablemente al voluntarismo. Deseo concentrarme en que es más evidente a Tomás que a Kant el que el placer es consecuencia de la virtud, que la satisfacción a nivel sensible que uno experimenta como resultado del deber cumplido está de acuerdo con el deseo de amarse a sí mismo, y por tanto, que siendo este deseo algo bueno y natural no es incorrecto actuar en virtud de dicho placer que es resultado de la virtud.

Esta delectabilidad de la virtud es explicada con cierta belleza estilística por él en los siguientes términos:

El virtuoso quiere sobre todo convivir consigo mismo, volviéndose sobre su corazón y meditando consigo mismo. Esto lo hace deleitablemente, de un modo, en cuanto a la memoria del pasado, porque el recuerdo de los buenos actos realizados le resulta deleitable; de otro modo, en cuanto a la esperanza del futuro, lo cual es deleitable para él; $y$ de un tercer modo, en cuanto al conocimiento del presente, pues según su mente es rico en meditaciones, en consideraciones verdaderas y útiles. ${ }^{22}$

Este texto no constituye definitivamente una alabanza al solipsismo. Se trata más bien de un encomio profundo y edificante del propio sujeto que vive en paz consigo mismo, porque sabe que ha operado de acuerdo con la parte más noble de su espíritu, a saber, de acuerdo con el dictamen de su inteligencia. Tratándose de un sujeto que ya es virtuoso, la virtud proporciona una satisfacción personal de orden sensitivo, en un proceso psicológico en que finalmente la inteligencia y el apetito sensible armonizan, convergen entre sí. Tomás no piega que el carácter sea lucha; es consciente de que la virtud se va fraguando en el combate espinoso con las dificultades, como corresponde a cualquier buen hábito por adquirirse. Pero al final de la batalla, cuando el propio sujeto logra imponerse a si mismo, disfruta de un estado de concordia consigo mismo. Pareciera 22 TOMAis DE AQUINO: In decem libros Ethicorum ad Nicomachum expositio, lib. IX,
lect. 4, n. 1808. como que finalmente llega un momento en que "la parte sensitiva está tan sujeta a la razón, que sigue el movimiento de la razón [espontáneamente], o por lo menos ya no se opone vehementemente a ésta", ${ }^{23}$ y esto siempre procura un placer. La conocida "sensación del deber cumplido" probablemente sea de esta misma naturaleza. ¿Podría pensarse en alguien que practicara lo que considera una virtud sin que se desencadenara en él alguna satisfacción personal como efecto de lo que hace? Con santo Tomás, es muy dificil pensar en un sujeto así.

Quizás sea por esto mismo que Fulton J. Sheen, solía hablar de la importancia que reviste el amor de sí mismo, frente a otro gran fenómeno sociopolítico con el que tuvo que lidiar durante varios años: el comunismo. Dice el otrora arzobispo de Nueva York:

¿Cómo sería posible amar a los demás en la medida en que me amo, si no me he amado antes? Por esta razón, la caridad evangélica rechaza el comunismo, porque al negar los derechos individuales, niega la dignidad de los entes individuales, el propio aprecio que puedan sentir por sí mismos los ciudadanos, su autoestima. Por tanto, la caridad cristiana exige una fuerte dosis de sacrificio en favor de los demás, pero esa entrega incansable hacia el prójimo no implica la renuncia absoluta de uno mismo ni la enajenación de mi persona y mis derechos en favor de la sociedad, pues de hacerlo, me quedaría sin ellos, lo que iría en contra de la propia inalienabilidad de los derechos naturales que el Estado protege, mas no crea. ${ }^{24}$

\footnotetext{
${ }^{23}$ In decem libros Ethicorum ad Nicomachum expositio, lib. IX, lect. 4, n. 1809. ${ }^{24} \mathrm{Y}$ añade que: "La filosofia comunista se basa precisamente en el valor de la masa y la insignificancia del individuo o persona. Marx dijo que el individuo, de y por sí El comunismo ningún valor a menos que sea miembro de la masa revolucionaria. "soviets", una perifica hormigueros, y las hormigas no son personas; para los "soviets", una persona es como un grano de uva que continúa existiendo sólo a condición de que su valor individual y personal sea exprimido fuera de él, de suerte que sólo exista en el vino del Estado" (La vida hace pensar..., p. 269).
} 
No hay que ser muy perspicaz para advertir que, aunque existe un mundo de diferencia entre el Nirvana budista y el Estado totalitario, desde el punto de vista del amor que cada persona pueda sentir por sí mismo, apenas la hay, ya que la falta de respeto por la personalidad humana, la menor o nula consideración que el propio sujeto pueda tener de sí mismo, es algo que se propugna desde ambas corrientes.

\section{El Amor a si mismo como medida de todo amor}

Junto al amor divino y el amor al prójimo, el amor de si mismo es uno de los tres tipos de amor que según Tomás puede el hombre desplegar en su inseparable condición de hombre y creatura. El santo no pasa por alto la convicción palpable de que el amor, cuando es auténtico, es desinteresado, en tanto que no se busca a sí mismo. De lo contrario, no tendría palabras tan elogiosas como las que destila por doquier hacia el amor al prójimo. Esto es verdad. Pero también lo es que al hombre, en el hacer el bien, lo primero es la satisfacción personal; y el bien de la otra persona está siempre en segundo lugar, si no, no lo hariamos. Si es verdad que el amor de sí mismo constituye un deseo natural de plenitud existencial, es decir que, es concomitante con el deseo de ser feliz, habrá que reconocer que cualquier otro tipo de amor a los demás es en cierto modo una forma de amor propio en su versión más sublime, o a lo menos, que el amor de sí mismo es la medida de todo amor a los demás hombres. Nadie amaria a los otros si no considerara que en ello radica la felicidad propia.

Parecería sorprendente el que se pretenda afirmar que en el amor de sí mismo pueda aprenderse lo que es todo amor. Pero esto es precisamente lo que enseña santo Tomás en el terreno propiamente filosófico y de la razón natural. Ya se sabe que santo Tomás irá más allá de esta parcela en el preciso lugar en que exponga teológicamente lo correspondiente a la caridad sobrenatural. En ésta, se puede admitir la entrega de la propia persona por el amado hasta la propia muerte, es decir, sin importar ya el deseo de conservar el propio ser, tal como Cristo lo hizo. El color rojo del indumento cardenalicio es el símbolo de que los mismos deben estar dispuestos a perder la propia sangre en pro de su propio rebaño, como de hecho ha sucedido históricamente. Esto que para Aristóteles sería una locura irracional como lo fue para los paganos en tiempos de Pablo, para Tomás es no sólo legítimo sino que puede llegar a ser incluso un deber. Por eso se trata de una virtud infusa, es decir, no natural.

Pero por ahora, permítaseme regresar al terreno natural, para decir nuevamente algo más sobre el amor de sí mismo. Cuando Aristóteles dice que "la forma más sublime de amistad es la que se parece al amor de sí mismo", 25 la interpretación que uno debe hacer de estas palabras, no debe ser según santo Tomás el que el amor de sí mismo sea un reflejo de la amistad, sino más bien todo lo contrario. Uno no se ama a sí mismo como se ama al amigo, antes bien se ama al amigo como se ama uno a si mismo. Por eso dice que "el amor al otro procede del amor que siente uno por la propia persona". ${ }^{26} \mathrm{Se}$ le desea un bien a las demás personas, en la medida en que se desea naturalmente el bien propio.

¿Sería correcto pensar que la caridad no puede aplicarse también al amor de sí mismo, y que únicamente se extiende al amor por los demás? Según Tomás, nada sería más incorrecto que pensar en ello. Porque sin duda alguna es verdad que el término caridad, genéticamente hablando, recibió por primera vez esa denominación para designar el amor que puede haber al menos entre dos personas. ${ }^{27}$ El propio Pseudo-Dionisio Areopagita solía referirse al amor como un poder unitivo, ${ }^{28}$ y para toda unión se requiere no de uno sino de diversos elementos. Sin embargo, el Angélico salva hábilmente la situación señalando con agudeza que: aquellas cosas que ya son uno numéricamente, puede que aún les haga falta unirse afectivamente. ${ }^{29}$ Es lo que sucede con un mismo sujeto, que aunque de suyo es algo uno, no reina en él cierta concordia consigo mismo,

${ }^{25}$ Ethica Nicomachea, 1166a, 1-2.

26 "Affectus amantis primo figitur in ipso amante, et ex eo derivatur ad alios" (Scriptum super Sententiis Petri Lombardi, lib. 3, d. 28, q. 1, a. 6. c.).

27 GREGORIO MAGNo (In Evan. I hom. 17: ML. 76, 1139) solia decir que: "caritas minus quam inter duos haberi non potest": citado por Tomás en Scriptum super Sententiis Petri Lombardi, lib. 3, d. 28, q. 1, a. 6, arg. 1.

${ }^{28} \mathrm{Cf}$. T. de AQUINo, In librum Beati Dionysii..., lect. X, cap. IV, n. 431.

${ }^{29}$ Scriptum super Sententiis, lib. 3, d. 28, q. 1, a. 6, ad 3um. 
no percibe la armonia que proviene de sentirse bien con uno mismo cuando se ha actuado de acuerdo con el deber, cuando se ha podido someter los propios deseos desordenados a la razón, e incluso cuando se es feliz con el propio matrimonio. La unidad afectiva, distinta de la unidad numérica, se produce cuando no reina la insatisfacción afectiva dentro de uno mismo. $Y$ por eso, hay que concluir que para Tomás "también el amor que alguien tiene para consigo mismo entra dentro de la caridad" ${ }^{30}$ ¿Por qué no creer que en muchos casos de depresión, lo que quizás está faltando para su tratamiento sea una fuerte dosis de caridad para consigo mismo? Si esto es verdad, el no "soportarse a sí mismo", quizás tenga que ver con una falta de aprecio por la propia persona.

El amor de sí mismo es algo superior a la amistad, del mismo

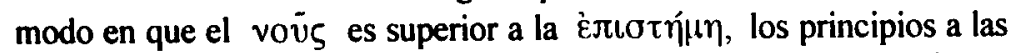
conclusiones, o la causa a lo causado ${ }^{31}$. Santo Tomás asi lo señala:

Hacia si mismo no se siente amistad, sino algo superior... Consigo mismo se vive en unidad, y este ser-uno está por encima del hacerse-uno con otro. Y de la misma forma que el ser uno es lo primero frente al hacerse uno con otro, así también es el amor que se tiene el hombre a sí mismo la forma primigenia y la raiz de la amistad. La amistad que sentimos hacia otro consiste en portarnos con él como con nosotros. ${ }^{32}$

Así, para que haya unión (unio) con el amigo tiene que haber antes unidad (unitas) para consigo mismo, pues como reza el apotegma, nemo dat quod non habet. La unidad siempre es mejor que la unión.

\section{Conclusión}

El amor de sí mismo, lejos de ser un acto egoísta y criticable, es no sólo necesario y útil sino además, un deber moral, porque se funda

\footnotetext{
${ }^{30}$ Scriptum super Sententiis, lib. 3, d. 28, q. 1, a. 6, c

${ }^{31}$ Scriptum super Sententiis, lib. 3, d. 28, q. 1, a. 6, c.

32 Summa Theologiae, II-II, q. 25, a. 4, c.
}

en el deseo de ser felices, un deseo completamente natural e involuntario. Nos están vedadas muchas cosas: pero el ser feliz no es una de ellas. Y tanto para Aristóteles como para Tomás, la virtud es algo necesario si se quiere ser feliz. Sin la virtud no se puede ser feliz porque todos quieren naturalmente ser felices. Por tanto, como la virtud es lo más bueno para el hombre, desearla es algo lícito y necesario. Si el hombre pensara que la virtud es inasequible, jamás se perfeccionaría.

Si al hombre no le fuera lícito amarse a si mismo, ello significaria que no le es lícito desear un bien para sí, y por tanto, ni siquiera la virtud. Y si no deseara la virtud jamás se perfeccionaría ni llegaría a ser bueno, con lo que la moral carecería de sentido. Pero además, tampoco llegaría a ser feliz, porque para Tomás, la virtud es un ingrediente fundamental de la felicidad. $Y$ como la felicidad es una exigencia de la propia naturaleza, el amor de si mismo también constituye una exigencia de plenitud existencial. De modo que una primera manera de caracterizarlo sea como una tendencia a la plenitud propia en cuanto lo más primario y la raíz de todo amor posterior.

El verdadero y legítimo amor de sí mismo no consiste en que cualquier hombre desee cualquier clase de bienes. Aunque es un hecho de la vida cotidiana que cada hombre quiere para sí mismo ciertos bienes (de hecho bien es aquello a lo que todos tienden naturalmente), el único que en realidad se ama, es el que quiere para si mismo, ser y vivir según aquello que en él permanece.

El que vive según aquello que en él cambia en realidad no se quiere, porque el que verdaderamente se ama no quiere dejar de ser lo que es. Y lo único que nos permite vivir según aquello que permanece en nosotros es vivir según el entendimiento y la razón, que es lo propio del virtuoso. Para Tomás, pues, el verdadero amor de sí mismo consiste en vivir conforme vive el virtuoso, es decir, siendo y viviendo según la propia razón, que, dentro de las facultades que integran a ser humano, es la menos sujeta a las mutaciones, y por tanto, lo único que le permitirá vivir sin dejar de ser lo que es. Asi es como finalmente adquiere sentido la célebre 
expresión tomista con que puede redondearse lo hasta aquí expresado: "el que se quiere siendo y viviendo principalmente según su cuerpo, que es algo que está sujeto a transformaciones, verdaderamente no se quiere siendo y viviendo". 33

\section{Bibliografia}

ARISTóTELES: Ética Nicomáquea, traducción de Julio Pallí Bonet, Gredos, Madrid, 2000, 300 pp.

-: Politica, traducción de Manuel Garcia Valdés, Gredos, Madrid, $2000,435 \mathrm{pp}$.

-: Retórica, traducción de Quintín Racionero, Gredos, Madrid, $2000,462 \mathrm{pp}$.

AQUINATIS, Thomae, In librum Beati Dionysii de divinis nominibus expositio, cura et studio: Ceslai Pera; Marietti, TauriniRomae, 1950, 431 pp.

-: De caritate, cura et studio: P.A. Odetto; Marietti, TauriniRomae, editio X, 1949, pp. 753-791.

AQuino, Tomás de: Comentario de la Ética a Nicómaco, traducción de Ana María Mallea, Ediciones CIAfIC, Buenos Aires, 1983, $607 \mathrm{pp}$.

-Suma de teologia, vol. 2, parte I-II, B.A.C., Madrid, 1989, 973 pp.

Suma de teologia, vol. 3, parte II-Il (a), B.A.C., Madrid, 1995, $612 \mathrm{pp}$.

BARTH, Paul: Los estoicos, traducción de Luis Recaséns Siches, Revista de Occidente, Madrid, 1930, 346 pp.

\footnotetext{
${ }^{33}$ In decem libros Ethicorum ad Nicomachum expositio, lib. IX, lect. IV, n. 1807.
}

IRALA, Narciso: Control cerebral y emocional, Librería Clavería, México, 1978, $288 \mathrm{pp}$.

SÉNECA, Lucio Anneo: Cartas a Lucilio, traducción de José M. Gallegos Rocafull, Secretaría de Educación Pública, México, 1985, $478 \mathrm{pp}$.

SHEEN, Fulton J.: La vida hace pensar, ed. Juan Flors, Barcelona, $1956,276 \mathrm{pp}$. 
Copyright of Tópicos. Revista de Filosofía is the property of Universidad Panamericana and its content may not be copied or emailed to multiple sites or posted to a listserv without the copyright holder's express written permission. However, users may print, download, or email articles for individual use. 